\title{
Implementation of Six Sigma Projects in Fortune 500 Companies* $^{*}$
}

\author{
Chamith Wasage \\ Bellevue University, Bellevue, NE, USA
}

\begin{abstract}
Six Sigma was introduced as a quality management tool at Motorola in the 1980s. Since then, leading U.S. companies have gained significant financial and non-financial benefits/results from the implementation of Six Sigma projects. Despite Six Sigma popularity, some companies have failed to gain quantifiable net financial benefits/results from Six Sigma implementation. In the process of Six Sigma implementation, vital components are critical factors and key ingredients for the success of Six Sigma projects because if these vital components do not exist, Six Sigma projects have little chance of success. Thus, this paper identifies most influencing and least influencing vital components. The results are generated from a survey conducted in U.S. Fortune 500 companies employing descriptive statistics. Based on the data analysis, "leadership commitment to Six Sigma” was the most influencing vital component and "overall, training on Six Sigma to reduce employee turnover" was the least influencing vital component.
\end{abstract}

Keywords: Six Sigma, Fortune 500 companies, vital components, critical success factor (CSF), quality management

\section{Introduction}

The costs of not doing things right the first time (quality costs) have a negative impact on a company's bottom-line (Antony \& Banuelas, 2002). To reduce these defects and quality costs, Motorola introduced and implemented the Six Sigma methodology in its processes in the 1980s. Since then, leading U.S. companies have gained significant financial and non-financial benefits/results from the implementation of Six Sigma. Indeed, through successful implementation of Six Sigma, research has found that leading U.S. Fortune 500 companies such as Motorola, Allied Signal, General Electric, Raytheon, Bank of America, Bechtel, and Caterpillar have reduced their defects and increased profitability (Anbari \& Kwak, 2004; Antony \& Banuelas, 2002; Gillett, Fink, \& Bevington, 2010; Greene, Ellis, Waller, \& Osborne, 2008).

Despite the Six Sigma success stories from these and other companies, Leahy (2010) discovered that some companies abandoned Six Sigma projects because they were not achieving positive net results within a specific period of time. In addition, "it is generally believed that only a small number of organizations that start this program succeed, where a large number of them fail” (Moosa \& Sajid, 2010, p. 747). Therefore, it is clear that the implementation of Six Sigma has yielded mixed results. This raises a critical question: What are the vital components (key ingredients/critical success factors (CSF)) for successfully implementing Six Sigma in Fortune 500 companies?

\footnotetext{
* Acknowledgement: The author would like to express sincere gratitude to Bellevue University for its support. Chamith Wasage, D.B.A., adjunct professor, College of Business, Bellevue University. Email: chamith.wasage@bellevue.edu.
} 
Vital components are the essential factors and critical ingredients that must be present in the implementation of Six Sigma (Antony \& Banuelas, 2002). If vital components are not present, the implementation of Six Sigma may not produce net positive benefits. Although previous research introduced some CSFs for successfully implementing Six Sigma, Antony and Banuelas (2002) claimed that most authors made few attempts to validate them using empirical research. Most studies (Antony, 2004; J. Antony, F. J. Antony, Kumar, \& Cho, 2007; Antony, Kumar, \& Labib, 2008; Antony \& Banuelas, 2002; Coronado \& Antony, 2002) were pilot surveys and non-probability sampling surveys (Kundi, 2005), rather than full-blown comprehensive surveys. In addition, they (Antony, 2004; J. Antony et al., 2007; Antony et al., 2008; Antony \& Banuelas, 2002; Coronado \& Antony, 2002; Kundi, 2005) have shown little interest in conducting comprehensive surveys on vital components and Six Sigma implementation in U.S. Fortune 500 companies. Therefore, the purpose of this research is to identify and analyze vital components for successful implementation of Six Sigma in U.S. Fortune 500 companies employing descriptive statistics.

\section{Brief Definitions of Six Sigma}

Many definitions and connotations are associated with Six Sigma. The methodology, however, can be fundamentally defined in management and statistical terms. From a management perspective, Six Sigma is a defect reduction strategy designed to improve quality in products and services, thereby reducing defects and improving quality to help exceed customer expectations. From a statistical point of view, Six Sigma uses the Greek letter "sigma" $(\sigma)$ to represent a standard deviation away from the mean. According to Gillett et al. (2010), "the sixth sigma is a representation of six standard deviations away from the mean of the population. In the most common use of Six Sigma, the goal is to create only 3.4 defects per million parts manufactured” (p. 26). Although different interpretations are associated with Six Sigma, the fundamental goal of Six Sigma remains the same; thus, it is a formal and disciplined methodology for defining, measuring, analyzing, improving, and controlling processes (Antony \& Banuelas, 2002). The Six Sigma DMAIC (Define, Measure, Analyze, Improve, and Control) methodology can be employed as a roadmap for process improvement. Table 1 defines each step of the process.

Table 1

Key Steps of DMAIC Process

\begin{tabular}{|c|c|}
\hline Steps & Key processes \\
\hline \multirow{3}{*}{ Define } & Define the requirements and expectations of the customer. \\
\hline & Define the project boundaries. \\
\hline & Define the process by mapping the business flow. \\
\hline \multirow{3}{*}{ Measure } & Measure the process to satisfy customers' needs. \\
\hline & Develop a data collection plan. \\
\hline & Collect and compare data to determine issues and shortfalls. \\
\hline \multirow{3}{*}{ Analyze } & Analyze the causes of defects and sources of variation. \\
\hline & Determine the variations in the process. \\
\hline & Prioritize opportunities for future improvement. \\
\hline \multirow{2}{*}{ Improve } & Improve the process to eliminate variations. \\
\hline & Develop creative alternatives and implement enhanced plan. \\
\hline \multirow{3}{*}{ Control } & Control process variations to meet customer requirements. \\
\hline & Develop a strategy to monitor and control the improved process. \\
\hline & Implement the improvements of systems and structures. \\
\hline
\end{tabular}

Note. Source: Adopted from Wang (2008, p. 2); Hekmatpanah, Sadroddin, Shahbaz, Mokhtari, and Fadavinia (2008, p. 367). 


\section{Six Sigma Benefits}

Previous research (Anbari \& Kwak, 2004; Antony \& Banuelas, 2002; Greene et al., 2008; Gillett et al., 2010; Pande, Neuman, \& Cavanagh, 2000) illustrated that many leading U.S. companies reduced process variation, improved quality, improved customer satisfaction, reduced defects, and increased profits and revenues through the implementation of Six Sigma. For example, Motorola saved \$15 billion over 11 years (Anbari \& Kwak, 2004). Table 2 indicates the key benefits gained by leading companies through Six Sigma implementation.

Table 2

Six Sigma Benefits

\begin{tabular}{|c|c|c|}
\hline Company/Project & Metric/Measures & Benefit/Savings \\
\hline Motorola (1992) & In-process defect levels & 150 times reduction \\
\hline Raytheon/Aircraft integration systems & Depot maintenance inspection time & Reduced $88 \%$ as measured in days \\
\hline GE/Railcar leasing business & Turnaround time at repair shops & $62 \%$ reduction \\
\hline $\begin{array}{l}\text { Allied Signal/Laminates plant in South } \\
\text { Carolina }\end{array}$ & $\begin{array}{l}\text { Capacity } \\
\text { Cycle time } \\
\text { Inventory } \\
\text { On-time delivery }\end{array}$ & \begin{tabular}{|l|} 
Up $50 \%$ \\
Down $50 \%$ \\
Down $50 \%$ \\
Increased to nearly $100 \%$ \\
\end{tabular} \\
\hline Allied Signal/Bendix IQ brake pads & Concept-to-shipment cycle time & Reduced from 18 months to 8 months \\
\hline \begin{tabular}{|l|l|} 
Hughes Aircraft's Missiles Systems \\
Group/Wave soldering operations
\end{tabular} & \begin{tabular}{|l|} 
Quality \\
Productivity
\end{tabular} & \begin{tabular}{|l|} 
Improved $1,000 \%$ \\
Improved 500\% \\
\end{tabular} \\
\hline General Electric & Financial & Savings of \$2 billion in 1999 \\
\hline Motorola (1999) & Financial & Savings of \$15 billion over 11 years \\
\hline Dow Chemical/Rail delivery project & Financial & $\begin{array}{l}\text { Savings of } \$ 2.45 \text { million in capital } \\
\text { expenditures }\end{array}$ \\
\hline DuPont/Yerkes Plant in New York (2000) & Financial & Savings of more than $\$ 2$ million \\
\hline Telefonica de Espana (2001) & Financial & $\begin{array}{l}\text { Savings and increases in revenue of } \$ 30 \\
\text { million euro in the first } 10 \text { months }\end{array}$ \\
\hline Texas Instruments & Financial & Savings of $\$ 600$ million \\
\hline Johnson \& Johnson & Financial & Savings of $\$ 500$ million \\
\hline Honeywell & Financial & Savings of $\$ 1.2$ billion \\
\hline
\end{tabular}

Note. Source: Adapted from Anbari and Kwak (2004, p. 3).

\section{What are the Vital Components?}

In the process of Six Sigma implementation, vital components are critical factors and key ingredients for the success of Six Sigma projects because if these vital components do not exist, Six Sigma projects have little chance of success (J. Antony et al., 2007; Kundi, 2005). If Six Sigma implementation fails to produce expected financial and non-financial benefits, organizations are wasting time and money. Therefore, it is critical to identify the most important vital components for the implementation of the Six Sigma process. A review of the literature presented the following vital components for the successful implementation of Six Sigma.

\section{Leadership and Management Practice}

Previous research (Antony, 2004; J. Antony et al., 2007; Antony et al., 2008; Antony \& Banuelas, 2002; Kundi, 2005) suggested that leadership commitment to Six Sigma and quality was an integral part of the successful implementation of Six Sigma. For example, Henderson and Evans (2000) noted that Jack Welch, CEO of GE, showed enthusiasm and commitment to quality to inspire the rest of upper management and the 
employees to get on board. Pande et al. (2000) believed that without upper management commitment to quality, Six Sigma implementation could produce weaker results. After reviewing the literature (Antony, 2004; J. Antony et al., 2007; Antony et al., 2008; Antony \& Banuelas, 2002; Kundi, 2005), the author has included the following vital components into the leadership and management practice construct: leadership commitment to Six Sigma, upper management commitment to quality, and leadership and upper management support of a Six Sigma budget.

\section{Linking Six Sigma to Human Resources}

Any organization fails or succeeds because of its employees. Thus, linking Six Sigma to human resources is an essential part of the successful implementation of Six Sigma (Antony \& Banuelas, 2002). After reviewing the literature (Antony \& Banuelas, 2002; Ho \& Chuang, 2006), the author has incorporated the following vital components into linking Six Sigma to the human resources construct: Six Sigma training during the hiring process; offering rewards and recognition for Six Sigma project employees; open ongoing communication between management and employees on Six Sigma project; providing employee training on Six Sigma belts (Green Belt, Black Belt, Master Black Belt, and Champion); employee training on project management, statistical tools, quality commitment, teamwork, and DMAIC/DFSS (Design for Six Sigma); and overall, training on Six Sigma to reduce employee turnover. All these vital components help reduce employees' anxiety and resistance to change for the new initiative. Overall, comprehensive Six Sigma training helps lower employee turnover.

\section{Linking Six Sigma to Customer}

As in any business strategy, Six Sigma initiatives should also be crafted to commence with customer needs and culminate with customer gratification. Six Sigma project leaders must understand customer needs, requirements, and expectations. Also, project leaders should listen to voice of the customer (VOC) to develop goals to meet customer expectations. Therefore, customer feedback, concerns, and suggestions are the key to providing superior product and service quality. The author has included the following vital components under linking Six Sigma to the customer construct: using customer concerns and feedback to improve quality. Table 3 illustrates the formation of constructs and vital components.

Table 3

Formation of Constructs and Vital Components

\begin{tabular}{|l|l|}
\hline Constructs & Vital components \\
\hline \multirow{4}{*}{ Leadership and management practice } & Leadership commitment to Six Sigma \\
\cline { 2 - 2 } & Upper management commitment to quality \\
\cline { 2 - 2 } & Leadership and upper management support of a Six Sigma budget \\
\hline \multirow{5}{*}{ Linking Six Sigma to human resources } & Six Sigma training during the hiring process \\
\cline { 2 - 2 } & $\begin{array}{l}\text { Offering rewards and recognition for Six Sigma project employees } \\
\text { project }\end{array}$ \\
\cline { 2 - 2 } & $\begin{array}{l}\text { Providing employee training on Six Sigma belts (Green Belt, Black Belt, Master } \\
\text { Black Belt, and Champion) }\end{array}$ \\
\cline { 2 - 2 } & $\begin{array}{l}\text { Employee training on project management, statistical tools, quality commitment, } \\
\text { teamwork, and DMAIC/DFSS }\end{array}$ \\
\cline { 2 - 2 } & Overall, training on Six Sigma to reduce employee turnover \\
\hline Linking Six Sigma to customer & Using customer concerns and feedback to improve quality \\
\hline
\end{tabular}




\section{Research Method, Data Collection, and Questionnaire Design}

As noted above, some companies abandoned Six Sigma because they did not achieve net positive financial and non-financial results as a result of their attempts at Six Sigma implementation (Leahy, 2010; Moosa \& Sajid, 2010). On the other hand, other companies have achieved the expected results from Six Sigma implementation (Anbari \& Kwak, 2004; Antony \& Banuelas, 2002; Greene et al., 2008; Gillett et al., 2010; Pande et al., 2000). This raises a critical question: What are the vital components (CSFs/key ingredients) for successfully implementing Six Sigma?

As discussed above, based on previous research, three major vital constructs were identified: (1) leadership and management practice; (2) linking Six Sigma to human resources; and (3) linking Six Sigma to customer. The first construct includes three item statements, the second construct consists of six item statements, and the third construct consists of one item statement. After extensively examining the related literature, the author has developed a survey questionnaire to collect data for the study. The questionnaire was developed to focus on Six Sigma operational matters in Fortune 500 companies. Whenever possible, questionnaire questions were examined, constructed, developed, and extracted from previously published Six Sigma research (Antony, 2004; J. Antony et al., 2007; Antony et al., 2008; Kundi, 2005; Pande et al., 2000). The questionnaire was examined and pilot tested by the four Six Sigma quality experts.

After reviewing the related research (Antony, 2004; J. Antony et al., 2007; Antony et al., 2008; Antony \& Banuelas, 2002), the author elected to employ the closed-ended Likert scale (from $1=$ strongly disagree to 6 = strongly agree) question format for most of this research because the data are in a quantifiable form, ensuring that statistical analysis can be used (J. Antony et al., 2007).

Respondents were asked to indicate whether or not they strongly agree (6), moderately agree (5), slightly agree (4), slightly disagree (3), moderately disagree (2), or strongly disagree (1) with each statement provided. After reviewing the data collection methods, the author decided to collect data by asking quality managers and quality professionals in Fortune 500 companies who have experienced Six Sigma to evaluate their experiences on the 10 items statements. The author also selected the mail survey (postal survey) method for this research because the nature of the required data and details would not be complex. In addition, in quality management and Six Sigma research, mail surveys have been a popular data collection method to statistically validate item statements (Antony, 2004; J. Antony et al., 2007; Antony et al., 2008; Antony \& Banuelas, 2002).

A total of 500 questionnaires were mailed to a company quality executive, quality manager, or quality director at each company on the 2011 Fortune 500 company list. With follow-up postcards, 54 companies responded to the survey. Only 51 companies, however, are using or have used the principals of Six Sigma; three companies have never used the principals of Six Sigma. A total of six questionnaires were returned to the author (sender) due to address changes. As a result, the response rate for the survey was $10.93 \%$. The first part of the survey was designed to capture demographic information of the respondents; the second part of the survey was intended to determine respondents' rating on the item statements on a 6-point Likert scale.

\section{Analysis of the Survey Demographic Data}

Six Sigma was initiated in the manufacturing industry. Thus, it has been used in the manufacturing industry since the 1980s. Recently, service companies such as healthcare, financial, insurance, and public agencies have begun to implement Six Sigma in their processes (J. Antony et al., 2007). The survey asked respondents to identify their primary business activity. Not surprisingly, the majority of respondents (53\% or 27) selected “manufacturing industry”. Figure 1 indicates companies’ primary business activity distribution. 


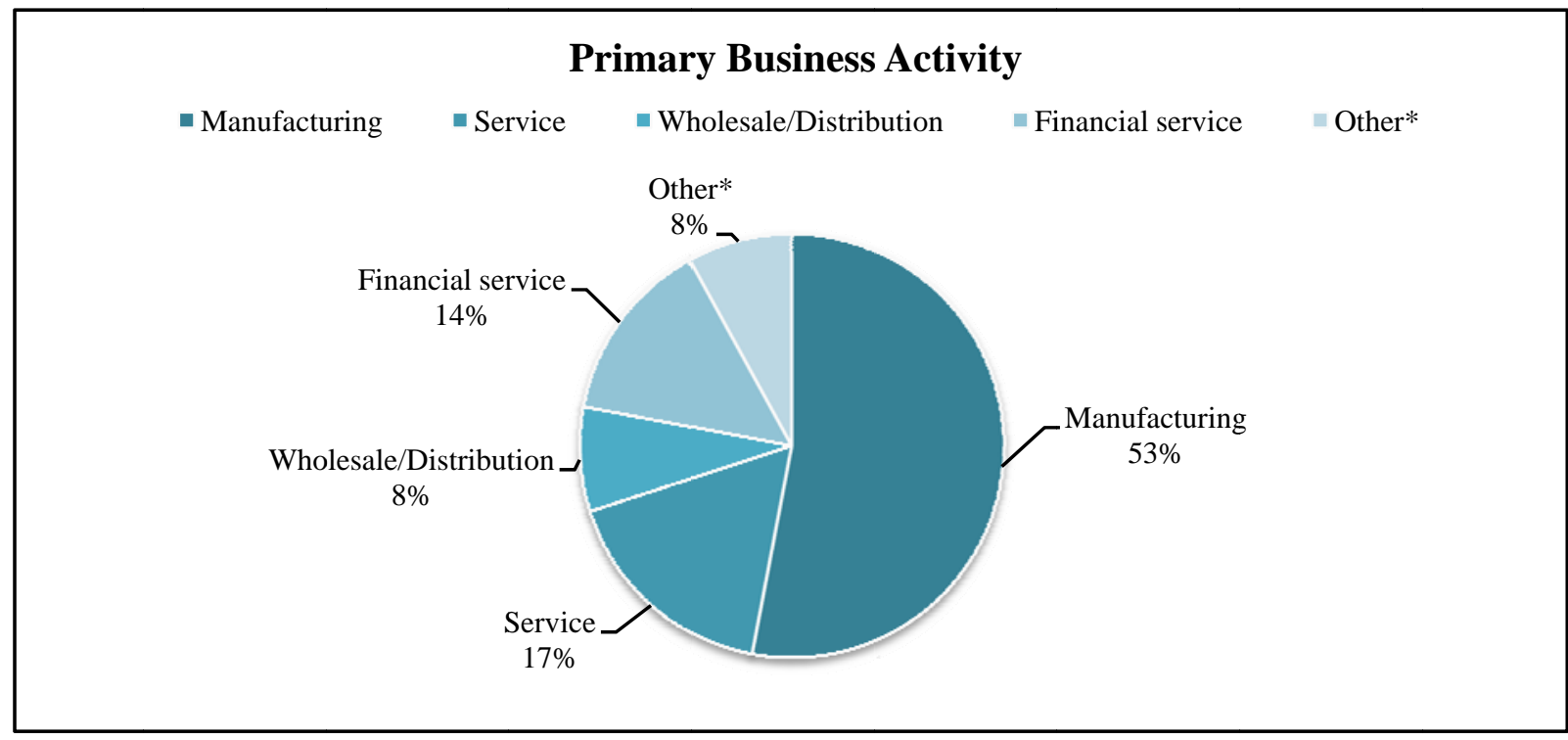

Figure 1. Types of business activities of the participants. Note. $N=51$; *: Utility and/or energy.

The largest group of the respondents in the survey had Master Black Belts (31\%) followed by Black Belts (21\%), no belts (17\%), Champions (15\%), and Green Belts (13\%). Approximately $41 \%$ of the companies had 151 or more Black Belt- and Master Black Belt-certified employees. Also, the majority of the respondents (27\%) have been implementing Six Sigma for 10 years or more. In addition, many respondents (58\%) using Six Sigma have also been using other quality initiatives such as Lean, ISO 9000, and ISO 9001 for at least seven years or more. From a Six Sigma benefit perspective, most respondents noted that they gained net financial benefits from Six Sigma implementation.

\section{Analyzing Vital Components from the Survey}

In this survey, the Cronbach's alpha coefficient analysis $(\alpha)$ was employed to measure internal consistency for the questionnaires. Previous studies (Antony \& Banuelas, 2002; J. Antony et al., 2007; Black \& Porter, 1996; Nunnally, 1978) indicated that a Cronbach's alpha coefficient of 0.6 or higher was an acceptable indication of internal consistency. All the items in the survey had a Cronbach's alpha greater than 6.0. In addition to the Cronbach's alpha coefficient analysis $(\alpha)$, the survey focused on three commonly discussed types of validity: content validity, construct validity, and criterion-related validity. As previously discussed, the survey questionnaire was based on previously published Six Sigma research (Antony, 2004; J. Antony et al., 2007; Antony et al., 2008; Antony \& Banuelas, 2002; Kundi, 2005; Pande et al., 2000). Overall, content validity, construct validity, and criterion-related validity tests produced acceptable results.

The respondents were asked to rate 10 items. They were given a 6-point Likert scale $(6=$ strongly agree, 5 = moderately agree, 4 = slightly agree, 3 = slightly disagree, 2 = moderately disagree, and 1 = strongly disagree) to rate the given statements. The mean score for each vital item determined the strength of the vital item. Each respondent's rating was vertically added together for each vital item and then divided by the number of respondents $(N=51)$ to generate the mean score of each item vital component. The higher scores demonstrate greater vital strength. The following table and figure indicate the mean scores and standard deviation of each item vital component. Table 4 demonstrates descriptive statistics for each vital component in a descending order and Figure 2 illustrates the mean score of each vital component in a descending order. 
Table 4

Descriptive Statistics for Each Vital Component

\begin{tabular}{lcccccccccc}
\hline Description & V1 & \multicolumn{1}{c}{ V2 } & V3 & V4 & V5 & V6 & V7 & V8 & V9 & V10 \\
\hline Mean & 5.75 & 5.69 & 5.59 & 5.41 & 5.35 & 5.25 & 5.06 & 4.25 & 3.65 & 3.35 \\
Median & 6 & 6 & 6 & 6 & 6 & 5 & 5 & 4 & 4 & 3 \\
Mode & 6 & 6 & 6 & 6 & 6 & 5 & 6 & 4 & 5 & 5 \\
Standard deviation & 0.44 & 0.47 & 0.61 & 0.85 & 0.93 & 0.63 & 1.29 & 1.00 & 1.52 & 1.45 \\
Range & 1 & 1 & 2 & 4 & 3 & 2 & 4 & 4 & 4 & 5 \\
Minimum & 5 & 5 & 4 & 2 & 3 & 4 & 2 & 2 & 1 & 1 \\
Maximum & 6 & 6 & 6 & 6 & 6 & 6 & 6 & 6 & 5 & 6 \\
Sum & 293 & 290 & 285 & 276 & 273 & 268 & 258 & 217 & 186 & 171 \\
Count $(N)$ & 51 & 51 & 51 & 51 & 51 & 51 & 51 & 51 & 51 & 51 \\
\hline
\end{tabular}

Note. V1 = Leadership commitment to Six Sigma; V2 = Upper management commitment to quality; V3 = Leadership and upper management support of a Six Sigma budget; V4 = Using customer concerns and feedback to improve quality; V5 = Employee training on project management, statistical tools, quality commitment, teamwork, and DMAIC/DFSS; V6 = Open communication between management and employees of Six Sigma projects; V7 = Providing employee training on Six Sigma belts (Green Belt, Black Belt, Master Black Belt, and Champion); V8 = Offering rewards and recognition for Six Sigma project employees; V9 = Six Sigma training during the hiring process; and V10 = Overall, training on Six Sigma to reduce employee turnover.

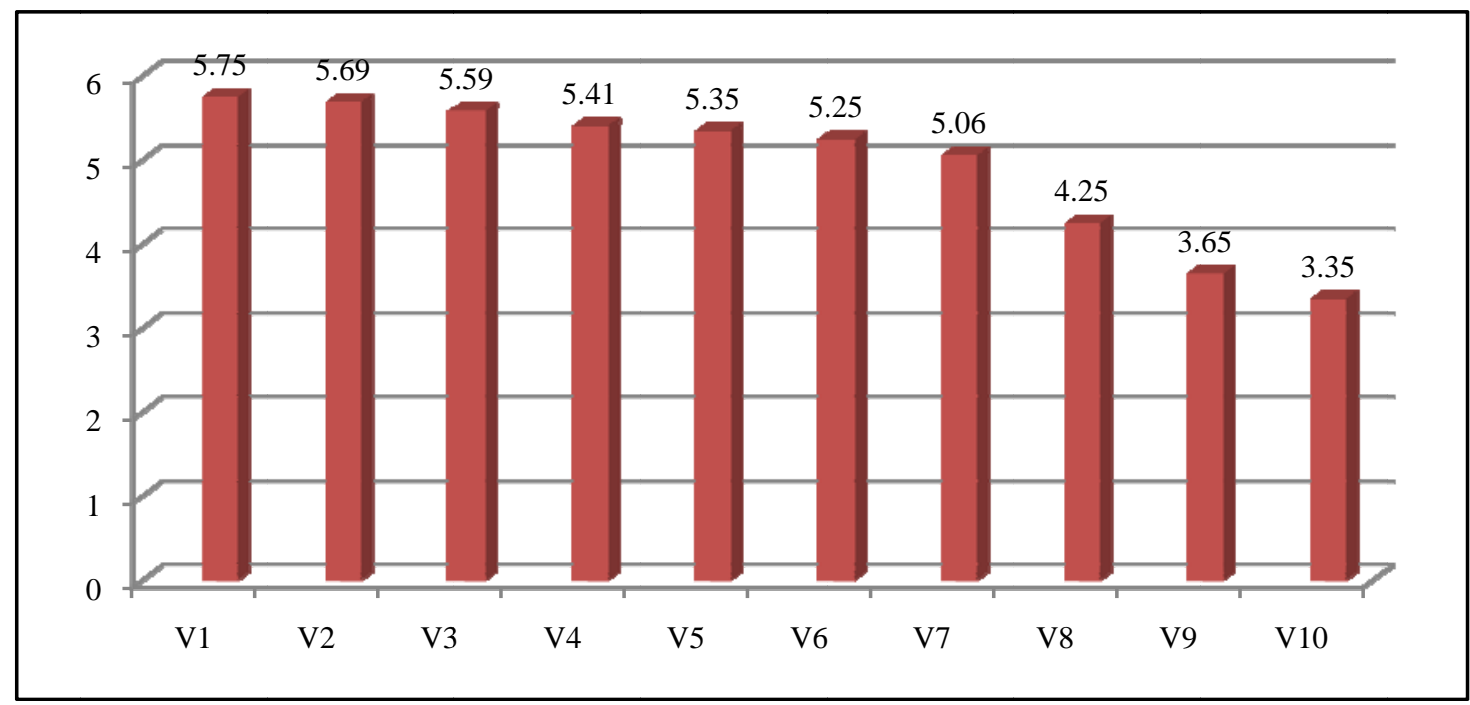

Figure 2. Mean score for each vital component.

As illustrated in Table 4 and Figure 2, leadership commitment to Six Sigma (V1), upper management commitment to quality (V2), leadership and upper management support of a Six Sigma budget (V3), and using customer concerns and feedback to improve quality (V4) had mean scores of more than 5.4, indicating that these vital components are essential to the successful implementation of Six Sigma. Most previous research (Antony, 2004; Antony \& Banuelas, 2002; J. Antony et al., 2007; Kundi, 2005; Eckes, 2000; Harry \& Schroeder, 2000; Pande et al., 2000) supported the above findings. It was surprising that Six Sigma training during the hiring process (V9) and overall, training on Six Sigma to reduce employee turnover (V10) ranked relatively lower than other vital components. It is, however, important to note that all vital components are essential to the successful implementation of Six Sigma (Antony \& Banuelas, 2002). If the implementation plan does not include all the vital components, companies may be wasting money, time, and resources. 


\section{Conclusion}

Previous research (Anbari \& Kwak, 2004; Antony \& Banuelas, 2002; Gillett et al., 2010; Greene et al., 2008) showed that many leading U.S. companies gained quantifiable net benefits from the successful implementation of Six Sigma projects. As a result, Six Sigma's popularity has been growing in recent years (Anbari \& Kwak, 2004). Contrasting research (Leahy, 2010; Moosa \& Sajid, 2010), however, suggests that some companies failed to achieve the desired benefits from Six Sigma implementation.

In the process of Six Sigma implementation, if vital components do not present, Six Sigma projects may not produce desired benefits. Based on this research, vital components influencing the successful implementation of Six Sigma include leadership commitment to Six Sigma (V1), upper management commitment to quality (V2), leadership and upper management support of a Six Sigma budget (V3), and using customer concerns and feedback to improve quality (V4). The survey also found that overall, training on Six Sigma to reduce employee turnover (V10) is the lowest ranked vital component. These results will help managers properly allocate their resources for Six Sigma quality projects during the implementation.

Although this research met its objectives, it was not without limitations. The research used a postal mailing method to collect data with Likert scale questions. Even with follow-up postcard reminders, the author received a relatively low response rate; more participants could produce better generalized results. The Likert scale questionnaire technique has some limitations. For example, the author was unable to determine why a particular rating was selected. Therefore, semi-structured interviews may produce more in-depth information about Six Sigma and its implementation (Antony \& Banuelas, 2002).

\section{References}

Anbari, F. T., \& Kwak, Y. H. (2004). Success factors in managing Six Sigma projects. Paper presented at the Project Management Institute Research Conference, London, UK, July 11-14.

Antony, J. (2004). Six Sigma in the UK service organizations: Results from a pilot survey. Managerial Auditing Journal, 19(8), 1006-1013.

Antony, J., \& Banuelas, R. (2002). Key ingredients for the effective implementation of Six Sigma program. Measuring Business Excellence, 6(4), 20-27.

Antony, J., Antony, F. J., Kumar, M., \& Cho, B. R. (2007). Six Sigma in service organizations: Benefits, challenges and difficulties, common myths, empirical observations and success factors. International Journal of Quality \& Reliability Management, 24(3), 294-311.

Antony, J., Kumar, M., \& Labib, A. (2008). Gearing Six Sigma into UK manufacturing SMEs: Results from a pilot study. Journal of the Operational Research Society, 59(4), 482-493.

Black, S. A., \& Porter, L. J. (1996). Identification of the critical factors of TQM. Decision Sciences, 27(1), 1-21.

Coronado, R. B., \& Antony, J. (2002). Critical success factors for the successful implementation of six sigma projects in organizations. The TQM Magazine, 14(2), 92-99.

Eckes, G. (2000). The Six Sigma revolution: How General Electric and others turned process into profits. New York, NY: John Wiley \& Sons.

Gillett, J., Fink, R., \& Bevington, N. (2010, April 1). How Caterpillar uses 6 Sigma to execute strategy. Strategic Finance, 25-28.

Greene, C. M., Ellis, B., Waller, M., \& Osborne, M. (2008). Six Sigma in the 21st century. Paper presented at the Industrial Engineering Research Conference, Vancouver, Canada.

Harry, M., \& Schroeder, R. (2000). Six Sigma: The breakthrough management strategy revolutionizing the world's top corporations. New York, NY: Doubleday.

Hekmatpanah, M., Sadroddin, M., Shahbaz, S., Mokhtari, F., \& Fadavinia, F. (2008). Six Sigma process and its impact on the organizational productivity. World Academy of Science, Engineering and Technology, 43, 365-369.

Henderson, K. M., \& Evans, J. R. (2000). Successful implementation of Six Sigma: Benchmarking General Electric Company. Benchmarking: An International Journal, 7(4), 260-282. 
Ho, L. H., \& Chuang, C. C. (2006). A study of implementing Six Sigma quality management system in government agencies for raising service quality. The Journal of American Academy of Business, 10(1), 167-173.

Kundi, O. H. K. (2005). A study of Six Sigma implementation and critical success factors. Paper presented at the Pakistan's 9th International Convention on Quality Improvement Conference, Lahore, Pakistan.

Leahy, M. (2010). Pre-work and prioritization mean fewer failed projects. Retrieved from http://isixsigma.com

Moosa, K., \& Sajid, A. (2010). Critical analysis of Six Sigma implementation. Total Quality Management \& Business Excellence, 21(7), 745-759.

Nunnally, J. C. (1978). Psychometric theory. New York, NY: McGraw-Hill.

Pande, P. S., Neuman, R. P., \& Cavanagh, R. R. (2000). The Six Sigma way: How GE, Motorola, and other top companies are honing their performance. New York, NY: McGraw-Hill.

Wang, H. (2008). A review of Six Sigma approach: Methodology, implementation and future research. Retrieved from http://www.fkm.utm.my/ noordin/Pdf\%20files/Review\%20paper\%201.pdf 